Mood matters: A response to Mellalieu

5

6

Andrew M. Lane

7

University of Wolverhampton, UK

8

Christopher J. Beedie

10

Canterbury Christ Church University College, UK

11

and

12

Matthew J. Stevens

13

University of Wolverhampton, UK

14

15

RESEARCH NOTE FINAL: May $19^{\text {th }} 2005$

16 
Abstract

2 
Mood matters: A response to Mellalieu

Psychological states such as mood, emotion, and affect have recently received a great deal of attention in the sport psychology literature (Hanin, 2000, 2003; Lane \& Terry, 2000; Lazarus, 2000; Mellalieu, 2003). Lane and Terry (2000) proposed a definition of mood and a conceptual model of mood and performance with a focus on depression. Mellalieu (2003) provided detailed commentary and analysis of this work. We argue that although Mellalieu's paper raised several important and justifiable concerns, in doing so it is arguably moving knowledge in circles rather than forwards. The present paper thus provides a response to Mellalieu's commentary with reference to recent research.

\section{Conceptual and measurement issues}

Lane and Terry’s (2000) proposal of a definition of mood stemmed in part from the absence of a commonly accepted definition in the sport psychology literature. Mood research was, to that date, characterized by use of the Profile of Mood States (POMS: McNair, Lorr, \& Droppleman, 1971), with researchers tending to focus on exploring differences in POMS subscale scores between athletes of different achievement, often with scant attention to the nature of mood itself, and to how and why the subscales assessed might influence performance (see Beedie, Terry, \& Lane, 2000). Lane and Terry defined mood as " $a$ set of feelings, ephemeral in nature, varying in intensity and duration, and usually involving more than one emotion" (p. 16).

Lane and Terry (2000) offered their definition of mood in part to provide greater clarity to their own findings, and in part to provide some tentative criterion by which other researchers in sport may operationalize the construct. This definition accompanied a model of mood-performance relationships, based on POMS scores, that sought to explain equivocal mood-performance research findings. Despite suggestions, based on meta-analysis results, that 
1 researchers should find an alternative measure to the POMS (e.g., Rowley, Landers, Kyllo, \&

2 Etnier, 1995), Lane and Terry argued for the need to develop a conceptual framework for the

3 POMS model of mood, and based this argument on the results of more recent meta-analyses

4 (see Beedie et al., 2000). The results of Beedie et al's analyses showed that POMS subscales

5 have some predictive validity but that there is a need to explain why anger and /or tension is

6 associated with good performance in some studies and poor performance in other studies.

7 Subsequent tests of Lane and Terry's model have supported the notion that scores on the

8 depressed mood scale are associated with high scores of anger, confusion, fatigue, tension and

9 low scores of vigor (Lane 2001; Lane \& Lovejoy, 2001; Lane, Terry, Beedie, \& Stevens,

10 2004; Lane, Terry, Beedie, Curry, \& Clark, 2001), that anger and/or tension is associated with

11 facilitated performance when accompanied by scores of zero on the depression scale, and that anger and/or tension are associated with debilitated performance when associated with

depressed mood (Lane et al., 2001, 2004). Thus, it may be argued that Lane and Terry's model represents a contribution to the literature in two respects. Firstly, the results above represent a plausible theoretical explanation for many of the apparently contradictory findings in previous mood-performance research. Secondly, Lane and Terry's model provides testable hypotheses for using the POMS, a measure that, despite much controversy, is still widely used by researchers and applied sport psychology consultants (Gould, Tammem, Murphy, \& May, 1989; Terry, 1995; Vealey \& Garner-Holman, 1998).

Mellalieu (2003) highlighted a number of concerns with Lane and Terry's (2000) work. He correctly identifies a limitation of Lane and Terry's definition of mood, in which the construct is defined in relation to emotion, a situation perhaps analogous to defining light in relation to darkness rather than as a phenomenon in its own right. Certainly there are clear problems with the definition in question. However, although providing detailed comment on 
1 this definition Mellalieu concludes by suggesting that future researchers provide their own definitions. From the pragmatic perspective such an approach may be justified, but, if one goal for research is to build a cogent body of knowledge, researchers must seek to build on such consensus, not simply develop a 'working definition' of emotion or mood that may serve their particular research question at the time, but not constitute a genuine contribution to emotion and mood theory per se. We argue that researchers should propose definitions with the dual, and explicit intentions of both clarifying their own research and of inviting subsequent authors to test and refine that definition.

Mellalieu (2003) discusses distinctions between emotion and mood. Lane and Terry (2000) argued that self-report measures such as the POMS cannot distinguish mood from emotion, and therefore, that attempts to distinguish them in research that used such a measure is difficult. Although Lane and Terry provided some discussion on differences between mood and emotion in terms of intensity, duration and specificity of the antecedent, it is evident that their definition of mood is heavily influenced by measurement issues. There is however, a wealth of research within general psychology that has sought to establish definitions that distinguish mood, emotion and affect (see Ekman \& Davidson, 1994). More recently, Ekkekakis and Petruzello (2002) have debated theoretical distinctions between these related concepts in the exercise psychology literature. It may be argued that, in providing their definition of mood, Lane and Terry sought to provide some theoretical background to using the POMS. It is acknowledged that such a strategy may hinder theoretical development; it is commonly agreed that psychological measures should be theory driven (Schutz, 1994; Thompson \& Daniel, 1996). Thus, if existing measures cannot distinguish mood from emotion, the first stage in future research should be establish the similarities and differences between mood and emotion and then either (a) develop a measure that can test these 
1 differences, and / or (b) use qualitative techniques to explore the nature of these differences

2 among athletes (see Hanin, 2003).

The wealth of research that has attempted to provide a definition of mood, affect and

4 emotion indicates that it is not an easy task (Beedie, Terry, \& Lane, in press, 2003, identified

565 papers offering opinion on this subject). Ekkekakis and Petruzello (2002) argued that

6 mood, emotion and affect are constructs that could be studied across a range of different

7 domains of human experiences and therefore definitions and measures of the constructs

8 should be global rather than specific to exercise or sport. Ekkekakis and Petruzello argued that

9 emotions are considered to be immediate responses to specific stimuli, characterized by a

10 relatively short duration and high intensity. Moods on the other hand are considered as lacking

11 a specific target and generally thought of as being less intense and longer lasting than

emotions (Parkinson, Totterdell, Briner, \& Reynolds, 1996). Affect refers to the experiential

13 component of all valenced (i.e., 'good' or 'bad') responses, including both moods and

14 emotions (Frijda, 1994). However, it is often argued that affect is the definition used by

researchers who wish to avoid defining whether their construct is a mood or an emotion (e.g.,

Watson \& Clark, 1997), and Dennett (1991) described affect as "the awkward term [for emotion] favored by psychologists" (p. 45).

Beedie et al. (in press, 2003) indicated that despite the volume of research interest,

there are no data relating to emotion-mood distinctions in the literature, therefore an analysis of the mood-emotion distinctions occurs only at a theoretical level. Beedie et al. conducted a content analysis of the academic literature that included 65 published works from sport and exercise psychology, general psychology, psychiatry and philosophy literature that attempted to distinguish mood from emotion. They also used qualitative techniques to explore 
1 Olympic medallists (despite some in-depth responses, not one of the 106 participants in this

2 study used the term 'affect'). Inductive content analysis revealed that among the 65

3 contributions to the academic literature, eight themes classifying emotion-mood distinction

4 emerged, with duration (62\% of authors), intentionality (41\%), cause (31\%), consequences

$5 \quad(31 \%)$ and function (18\%) the most frequently cited, with intensity, physiology, and awareness

6 of cause being cited less frequently. Similar inductive content analysis of responses from 106

7 participants identified 16 themes, with awareness of cause (65\% of respondents), duration

8 (40\%), and consequences (14\%) the commonly cited distinctions. When the eight themes cited

9 by both academics and non-academics were rank ordered, approximately $60 \%$ overlap in

10 opinion was evident.

11 An analysis of the nature of commonly agreed distinctions indicates that for

12 differences between mood and emotion for the category cause suggests that "Emotions are

13 caused by specific events localized in time, whereas moods build up as a consequence of

14 either a concatenation of minor incidents, persistent conditions in the environment, and/or internal metabolic or cognitive processes" (Parkinson et al., 1996, p. 6). For consequences,

16 Davidson (1994) argued that mood biases cognition whereas emotion biases behavior, where

17 the notion that the autonomic activity associated with emotion prepares the organism for 18 activity (e.g., the fight or flight response) whereas moods influence cognitive processes such 19 as information processing and memory, is widely espoused. For intentionality, it is suggested 20 that moods are unfocused, emotions are directed at specific objects. Although Beedie et al. (in 21 press, 2003) argued their findings do not provide solid evidence of differences between mood 22 and emotion, their findings certainly offer a consensus of published works and the opinion of 23 a non-academic population. 
Beedie, Lane, and Terry (2001) used content analysis of the academic literature to develop a scale to distinguish anxious mood from anxious emotion for use in sport (Beedie, Lane, \& Terry, 2004). Beedie et al. proposed that mood and emotion could be distinguished empirically if the context (i.e., the individual's awareness of the antecedents, focus, and likely consequences) is assessed in line with theoretical distinctions. They developed two five-item scales of statements describing emotion (i.e., anxiety focused on particular events and goals, such as "I am nervous about the event" and "I am anxious about not performing well in this event") and mood (i.e., anxiety neither caused by nor focused on a particular event, such as "I feel nervous at the moment for no particular reason" and "at the moment I am anxious about the future in general"). Confirmatory factor analysis results indicated that anxious mood and emotion could be distinguished empirically if the context (i.e., the individual's awareness of the antecedents, focus, and likely consequences) was assessed in line with theoretical distinctions. It should be noted that anxious mood correlated strongly with anxious emotion, and therefore although distinguishable, the two constructs appear highly related. Mellalieu (2003) argued that researchers can assess mood, affect and emotion using different scales, suggesting the Positive and Negative Affect Schedule (PANAS: Watson, Clark, \& Tellegen, 1988) assesses affect rather than mood. In addition, authors propose that the PANAS-X is a specific measure of emotion (Watson \& Clark, 1991) that has been used to assess emotion in sport in several studies (Bouffard \& Crocker, 1992; Crocker \& Graham, 1995; Walsh, Crocker \& Bouffard, 1992). Caution is urged in this respect: The semantics of emotion and mood are problematic, and many theorists support the notion that psychological states such as anxiety can exist as either a mood or an emotion (e.g., Lazarus, 1994). A questionnaire item 'anxious' may therefore represent either emotion or mood, and the implications for measurement are clear. For example, the PANAS has 'shared' items with 
1 other scales proposed to assess different constructs using the same response timeframe (i.e.,

2 How do you feel right now?). An example is the item 'I feel nervous', which appears in the

3 PANAS, where it is proposed to assess 'affect', which also appears in the POMS, where it is

4 proposed to assess 'mood' and which similarly appears in the Competitive State Anxiety

5 Inventory-2 (Martens, Vealey, Burton, Bump, \& Smith, 1990), where it is proposed to assess

6 somatic anxiety. Thus, Mellalieu's suggestion that researchers select an appropriate measure

7 to assess their chosen construct becomes problematic as a degree of semantic crossover is

8 evident in the items of measures purporting to measure diverse constructs.

Given problems with existing validated measures and the fact that Beedie et al.'s

10 (2001) measure requires further validation, it could be argued that a more fruitful line of

11 investigation is to explore athlete's understanding of differences between mood and emotion.

12 A recent study by Ruiz and Hanin (2004) used a symbolic representation method to explore

13 how athletes describe performance-related states through the use of metaphors (Hanin, 1997,

14 2000; Hanin \& Stambulova, 2002). As expected, data were highly individualized but did

distinguish emotions from moods, and suggest that qualitative techniques may allow athletes

to explain the context and personal meaning of affective states experienced in competition.

17 Ruiz and Hanin used Lazarus' (2000) work on emotion to inform mood-emotion distinctions, a strategy that would allow qualitative research to support or refute existing theory and thereby offer a means through which knowledge of mood and emotion in sport might differ in 20 practice.

It is also argued that there is a need for data on the strategies used by applied sport psychology consultants in relation to scores on psychometric instruments, for example, an athlete who scores ' 4 ' on the depression scale on the POMS. It is questionable whether structure (e.g., the intensity or duration of the state) can be used as a reliable basis for 
1 distinguishing mood, affect and emotion. Several authors have suggested that emotions are

2 more intense and less enduring than moods (e.g., Ekman \& Davidson, 1994). However, it

3 seems plausible to argue that a low intensity and enduring/repeated episode of anxiety focused

4 on an upcoming competition (i.e., an emotion by common convention) may be less intense

5 than a moderately intense state of anxiety that is not focused on any particular object event.

6 Jones (2003) urged practitioners to explore whether the affective response was a mood or an

7 emotion and then determine whether the intervention should be tailored accordingly.

8 Mellalieu (2003) argued that anxiety and stress tend to pre-emanate in the build up to

9 competition, assuming these states to be emotional responses to competition. It is arguable

10 that competition might be one of many stressors that interact to maintain the intense response

11 during the pre-competition period. A theory-led approach to an intervention in which the

12 practitioner seeks strategies for tackling emotional response (where the individual is aware of

13 the cause) from mood (where the cause is not focused) would seem appropriate.

14 We suggest that researchers and practitioners interested in working with emotion

15 and/or mood within sport should use commonly agreed definitions. The following two

16 definitions arguably best capture the nature of emotion and mood and are portrayed by the

17 literature and recent data (Beedie et al., in press, 2003). Lazarus (2000) offered the following

18 definition of emotion as "an organized psychophysiological reaction to ongoing relationships

19 with the environment...what mediates emotions psychologically is an evaluation, referred to

20 as an appraisal, of the personal significance for the well-being that a person attributes to this

21 relationship (...relational meaning), and the process” (p. 230). Parkinson et al. (1996)

22 proposed that "mood reflects changing non-specific psychological dispositions to evaluate,

23 interpret, and act on past, current, or future concerns in certain patterned ways" (p.216). 
We suggest that researchers interested in investigating the nature of mood and emotion

2 within sport should consider using the measure developed by Beedie et al. (2001), although

3 these authors recognize that further validation work is needed, or develop their own scale

4 from principles described above and elsewhere (see Ekman \& Davidson 1994). Alternatively,

5 researchers might wish to use the array of qualitative techniques suggested by Hanin (2003)

6 and explore the nature of emotion and mood from the perspective of athletes, a strategy

7 consistent with Jones' (2003) suggestions of addressing mood-emotions distinctions from an

8 applied perspective. Both of these suggestions should be the focus of future research.

9 Mellalieu's conceptual model

Mellalieu (2003) proposed a model to address his concerns on Lane and Terry's

11 model. The model is based on Cerin, Szabo, Hunt, and Williams' (2000) model in which mood is proposed to influence the appraisal process of numerous factors such as emotional

13 responses, perceived importance of competition, and coping efforts. Whilst such a model is

14 praiseworthy in attempting to organize a number of different variables into a theoretical framework, the model seems overly complex and difficult to test. Crocker and Graham (1995)

16 proposed four advantages of theory-driven research. First, theory delimits the field of research,

17 helping to prevent the researcher from being overwhelmed by the complexity of the issue.

Second, theory provides a conceptual framework which assists grouping research findings into logical units. Third, theories have systematic and heuristic effects that allow for development in the construction of knowledge and the inspiration of new research activity. Fourth, theorydriven research has the additional advantage of guiding construct measurement and statistical analyses. We argue that Mellalieu's model meets only the second and third benefits as suggested by Crocker and Graham, and limitations regarding one and four are likely to prevent

24 a rigorous test of the model, and hence thwart theory development. 


\section{Conclusion}

Mellalieu's (2003) response to Lane and Terry's (2000) paper emphasizes research

3 interest in mood and emotion in sport. Lane and Terry's model represents a shift to more

4 theory driven research, albeit through the theoretical framework derived from the POMS

5 model of mood, a model that is not without its limitations. Although Mellalieu raised a

6 number of pertinent issues, the relationship between theory development, construct

7 measurement and theory testing needed further explanation. We suggest that researchers use

8 established definitions of mood and emotion within sport, and employ rigorous methods that

9 are sensitive to the similarities and differences within each construct to do so. Theory and

10 measurement are inextricably linked and only through the use of valid methods will a clearer

11 understanding of the nature of mood and emotion in sport emerge.

12 
References

Beedie, C. J., Lane, A. M., \& Terry, P. C. (2001). Distinguishing emotion from mood in psychological measurement: A pilot study examining anxiety. Journal of Sports Sciences, 19, 69-70.

Beedie, C. J., Lane, A. M., \& Terry, P. C. (2004). Distinguishing emotion and mood components of pre-competition anxiety among professional rugby players. Journal of Sports Sciences.

Beedie, C. J., Terry, P. C., \& Lane, A. M. (2000). The Profile of Mood States and athletic performance: Two meta-analyses. Journal of Applied Sport Psychology, 12, 49-68.

Beedie, C. J., Terry, P. C., \& Lane, A. M. (2003). A comparison of academic and nonacademic distinctions between emotion and mood. Journal of Sports Sciences, 21, 340.

Beedie, C. J., Terry, P. C., \& Lane, A. M. (in press). Distinguishing mood from emotion. Cognition and Emotion.

Bouffard, M., \& Crocker, P. R. E. (1992). Coping by individuals with physical disabilities to perceived challenge in physical activity: Are people consistent? Research Quarterly for Exercise and Sport, 63, 410-417.

Cerin, E., Szabo, A., Hunt, N., \& Williams, C. (2000). Temporal patterning of competitive emotions: A critical review. Journal of Sports Sciences, 18, 605-626.

Crocker, P. R. E., \& Graham, T. R. (1995). Emotion in sport and physical activity: The importance of perceived individual goals. International Journal of Sport Psychology, 26, 117137.

Davidson, R. J. (1994). On emotion, mood and related affective constructs. In P.

Ekman \& R. J. Davidson (Eds.), The nature of emotion (pp. 51-55). Oxford, England: Oxford University Press. 
Dennett, D. C. (1991). Consciousness explained. New York: Little, Brown and Co. Ekkekakis, E., \& Petruzzello, S. J. (2002). Analysis of the affect measurement conundrum in exercise psychology: IV. A conceptual case for the affect circumplex. Psychology of Sport and Exercise, 3, 35-63.

Ekman, P., \& Davidson, R. J. (Eds.). (1994). The nature of emotion. Oxford, England: Oxford University Press.

Frijda, N. H. (1994). Varieties of affect: Emotions and episodes. Moods and sentiments. In P. Ekman \& R. J. Davidson (Eds.), The nature of emotion (pp. 59-67). Oxford, England: Oxford University Press. Gould, D., Tammem, V., Murphy, S., \& May, J. (1989). An examination of US Sport Psychology Consultants and the services they provide. The Sport Psychologist, 3, 300-312. Hanin, Y. L. (1997). Emotions and Athletic Performance: Individual Zones of Optimal Functioning Model. European Yearbook of Sport Psychology, 1, 29-72. Hanin, Y. L. (2000). Successful and poor performance and emotions. In Y. Hanin (Ed.), Emotions in sport (pp. 157-189). Champaign, IL: Human Kinetics. Hanin, Y. L. (2003, February). Performance Related Emotional States in Sport: A Qualitative Analysis [48 paragraphs]. Forum Qualitative Sozialforschung / Forum: Qualitative Social Research [On-line Journal], 4(1). Available at: http://www.qualitativeresearch.net/fqs-texte/1-03/1-03hanin-e.htm [Feb 26, 2003].

Hanin Y., \& Stambulova, N. B. (2002). Metaphoric description of performance states: An application of the IZOF model. The Sport Psychologist 16 (4), 396-415. 
Lane, A. M. (2001). Relationships between perceptions of performance expectations

and mood among distance runners; the moderating effect of depressed mood. Journal of Science and Medicine in Sport, 4, 235-249.

Lane, A. M., \& Lovejoy, D. J. (2001). The effects of exercise on mood changes: The moderating effect of depressed mood. Journal of Sports Medicine and Physical Fitness, 41, 539-545.

Lane, A. M., \& Terry, P. C. (2000). The nature of mood: Development of a conceptual model with a focus on depression. Journal of Applied Sport Psychology, 12, 16-33.

Lane, A. M., Terry, P. C., Beedie, C. J., \& Stevens, M. (2004). Mood and concentration grid performance: The moderating effect of depressed mood. International Journal of Sport and Exercise Psychology, 2, 133-145.

Lane, A. M., Terry, P. C., Beedie, C. J., Curry, D. A, \& Clark, N. (2001). Mood and performance: test of a conceptual model with a focus on depressed mood. Psychology of Sport and Exercise, 2, 157-172.

Lazarus, R. S. (1994). The stable and the unstable in emotion. In P. Ekman \& R. J. Davidson (Eds.), The nature of emotion (pp. 79-85). Oxford, England: Oxford University Press.

Lazarus, R.S. (2000). How emotions influence performance in competitive sports. The Sport Psychologist, 14, 229-252.

Martens, R., Vealey, R. S., Burton, D., Bump, L., \& Smith, D. E. (1990). Development and validation of the Competitive Sports Anxiety Inventory-2. In R. Martens, R. S. Vealey, \& D. Burton (Eds.), Competitive anxiety in sport. (pp. 117-178). Champaign, IL: Human Kinetics. 
McNair, D. M., Lorr, M., \& Droppleman, L. F. (1971). Manual for the Profile of Mood States. San Diego, CA: Educational and Industrial Testing Services.

Mellalieu, S. D. (2003). Mood matters: But how much? A comment on Lane and Terry (2000). Journal of Applied Sport Psychology, 15, 99-114.

The Psychology of Mood and Mood Regulation. London: Longman.

Rowley, A. J., Landers, D. M., Kyllo, L. B., \& Etnier, J. L. (1995). Does the Iceberg Profile discriminate between successful and less successful athletes? A meta-analysis. Journal of Sport and Exercise Psychology, 16, 185-199.

Ruiz, M. C., \& Hanin, Y. L. (2004). Metaphoric description and individualized emotion profiling of performance related states in high-level karate athletes. Journal of Applied Sport Psychology, 16, 1-16. psychology. In S. Serpa, J. Alves, J., \& V. Pataco (Eds.), International Perspectives on Sport and Exercise Psychology. (pp. 35-57). Morgantown, Fitness Information Technology, Inc. Terry, P. C. (1995). The efficacy of mood state profiling among elite competitors: A review and synthesis. The Sport Psychologist, 9, 309-324.

Thompson, B., \& Daniel, L. G. (1996). Factor analytic evidence for the construct validity of scores: A historical overview and some guidelines. Educational and Psychological Measurement, 56, 197-208.

Vealey, R. S., \& Garner-Holman, M. (1998). Applied Sport Psychology: Measurement issues. In Duda, J. L. (1998). Advances in sport and exercise psychology measurement, Morgantown, WV, Fitness Information Technology, pp-433-446. 
Walsh, J., Crocker, P.R.E., \& Bouffard, M. (1992). The effects of perceived

2 competence and goal orientation on affect and task persistence in a physical activity skill. The

3 Australian Journal of Science and Medicine in Sport, 24, 86-90.

4 Watson, D., \& Clark, L. A. (1991). The PANAS-X: preliminary manual for the 5 positive and negative affect schedule — expanded form (unpublished manuscript). Watson, D., \& Clark, L. A. (1997). Measurement and mismeasurement of Mood:

7 Recurrent and emergent issues. Journal of Personality Assessment, 68, 267-296.

9 measures of positive and negative affect: The PANAS scales. Journal of Personality and

10 Social Psychology, 54, 1063-1070. 